\title{
Some Notes on Grinnellia americana in Culture
}

\author{
Jun-ichi TsUKIDATE*
}

(Received July 14, 1970)

Several algae grown in the laboratory have sometimes provided interesting facts. In bacteria-free culture, the transformation of the normal polysiphonous stem becoming contorted or uniseriate with swollen cells, and the normal thalloid plant growing into a filamentous form has been demonstrated. These facts cannot be explained simply by different physical or chemical environments, such as temperature, light intensity, light duration and so on.

Grinnellia americana (C. AgARdH) HARveY, one of the red algae, has been grown in the laboratory and provided some fascinating results. In the culture with coastal water of Tokyo Bay, the plant grew slowly, putting out protuberance like branches which in turn put out branchlets, giving the plant an appearance like a filamentous alga. In contrast, plants cultured with water collected off-shore in Tokyo Bay grew normally. Both cultures were put under the same cultural condition, but were not in bacteria-free. It is thought that microorganisms in the off-shore water are different from those in the coastal water, and consequently the substances secreted or excreted by the microoganisms were not the same. In other words, some substances which promote the intrinsic metabolism of Grinnellia americana might be contained in the off-shore water.

An attempt was made in this paper to find out what substances are important on the morphogenesis of Grinnellia americana in culture. The work was conducted while the writer worked at the Tokai Regional Fisheries Research Laboratory during the period 1965 to 1969 . Although the investigations are sitll under way, the data presented should be valuable.

\section{Material and Methods}

Material. Grinnellia americana is a thalloid plant belonging to the family Delesseriaceae, and as yet has not been described from Japan.

The alga grows on stones or rocks in comparatively deep water and some of them drifted into the shore.

The alga was collected on the coast of Woods Hole, U.S.A., in August 1964. After rapid transport to the laboratory of New York it was put into Petri dish with the sea water of Woods Hole. Carpospores were seen on the bottom of Petri dish after 2 days.

* Nansei Reg. Fish. Res. Lab., Oono-chyo, Saeki-gun, Hiroshima Pref. (月館潤一: 南西海区水産 研究所). 
The material plants used in the experiment were derived from the tetraspores shed from the plants cultured in the sea water of Woods Hole and which resulted from the carpospores referred to the above. Maintenance of this species was achieved by the successive culture of the plants arising from rhizoids, which are easily formed in the sea water at the laboratory.

Media. Media employed were as follows:

Medium 1. Natural sea water collected at the entrance of Tokyo Bay

Medium 2. Natural sea water from Urayasu, at the bottom of Tokyo Bay

Medium 3. Artificial sea water (Table 1)

Medium 4. Enrichment solution (Table 2)

Table 1. Composition of artificial sea water.

$\begin{array}{lc}\mathrm{NaCl} & 2.4 \% \\ \mathrm{MgSO}_{4} \cdot 7 \mathrm{H}_{2} \mathrm{O} & 0.8 \% \\ \mathrm{KCl} & 70 \mathrm{mg} \% \\ \mathrm{CaCl}_{2} \cdot 2 \mathrm{H}_{2} \mathrm{O} & 55 \mathrm{mg} \% \\ \mathrm{NaHCO}_{3} & 16.8 \mathrm{mg} \% \\ \mathrm{NaNO}_{3} & 20 \mathrm{mg} \% \\ \mathrm{Na}_{2} \text { glycero } \mathrm{PO}_{4} & 2.5 \mathrm{mg} \% \\ \mathrm{Metal}^{\circ} \text { solution } & 1 \mathrm{ml} / 100 \mathrm{ml}\end{array}$

Table 2. Composition of enrichment solution.

\begin{tabular}{lc} 
Pure water & $100 \mathrm{ml}$ \\
$\mathrm{NaNO}_{3}$ & $350 \mathrm{mg}$ \\
$\mathrm{Na}_{2}$ glycero $\mathrm{PO}_{4}$ & $50 \mathrm{mg}$ \\
$\mathrm{FeCl}_{3} \cdot 6 \mathrm{H}_{2} \mathrm{O}$ & $12 \mathrm{mg}$ \\
Metal solution & $25 \mathrm{ml}$ \\
Vitamin $\mathrm{B}_{12}$ & $15 \gamma$ \\
Tris & $500 \mathrm{mg}$ \\
\hline
\end{tabular}

The natural sea waters were used within several months to over 1 year after collection. In this time the sea waters were preserved in a polyethylene bottle. The medium 3 was for culturing Porphyra sp. for the study of physiology. Enrichment solution was composed of constituents of ASW ${ }^{11}$ that was available to the writer.

Culture. All the media were sterilized for 30 minutes under the pressure of $1 \mathrm{~kg}$ / cmi. Before the experiments started, the materials were dipped in antibiotic solution (Table 3) for between 3 and 7 days and then dragged 7 or 8 strokes on the $1 \%$ agar and pure water in a Petri dish.

Table 3. Antibiotics solution.

\begin{tabular}{lc} 
Medium 3 & $50 \mathrm{ml}$ \\
Penicillin $\mathrm{G}$ & $200,000 \mathrm{unit}$ \\
Dihydro streptomycin $\mathrm{H}_{2} \mathrm{SO}_{4}$ & $1 \mathrm{~g}$ \\
\hline
\end{tabular}


The cultures were incubated at $15-18^{\circ} \mathrm{C}$, illuminated with fluorescent light of approximately 3,000 lux intensity, on a 9-15 to $12-12$ light-dark cycle.

\section{Results}

Experiment 1. Cultures were started with a normal form of Grinnellia americana in the medium 1 and 2. The experiment was repeated several times and results obtained were all the same with 1 exception. The plant with medium 1 grew into a normal thalloid form as seen in the sea but the plant with medium 2 grew producing an abnormal filamentous form with protuberances like branches. A microscopical observation showed that the filamentous form appeared to be the result of the gathering of newly divided cells.

Experiment 2. Cultures were started with the filamentous form occurring in experiment 1. The base medium was medium 1 with addition of $2 \mathrm{ml}$ of medium 4 per $100 \mathrm{ml}$. The results were inconsistent and provided the following forms: still remained as filametnous form; converted to normal thalloid form; initially converted to normal thalloid form and then protuberances like filaments appeared.

Experiment 3. As experiments 1 and 2 had suggested that the transformation of form was derived from the micronutrients contained in the sea water, the following experiment was designed to find out the effect of the vitamin B group on the growth or the form of Grinnellia americana. The vitamins employed and their quantities were as follows (Table 4):

Table 4. Vitamins added to culture solutions.

\begin{tabular}{l|ccc}
\multicolumn{1}{c|}{ Vitamins } & \multicolumn{3}{c}{ Quantities } \\
\hline B $_{1}$, thiamine & 10, & 30, & $100 \% \%$ \\
B $_{2, \text { riboflavin }}$ & 0.5, & 1, & $5 \% \%$ \\
B $_{6}$, pyridoxine & 1, & 5, & $10 \% \%$ \\
B $_{12}$, cyanocobalamin & $10 \mathrm{~m} \gamma, 30 \mathrm{~m} \gamma$, & $100 \mathrm{~m} \gamma \%$ \\
B $_{13}$, orotic acid & 10, & 30, & $100 \% \%$ \\
\hline
\end{tabular}

The culture solution employed in experiment 3 was medium 3. Both filamentous forms and thalloid forms were used as inocula. The normal thalloid form of the plant grew normally and with the best growth on $\mathrm{B}_{12}$.

The abnormal filamentous form sometimes grew into a thalloid form though in most cases it remained as the filamentous form irrespective of the type of vitamin. However $\mathbf{B}_{12}$ worked on the morphogenesis of Grinnellia americana in some instances.

Experiment 4. Amino acids were tested for effect on the growth or the form. The culture solution was medium 3 and the inocula employed were both filamentous and thalloid forms. The amino acids tested and their quantities employed were as follows (Table 5): 
Table 5. Amino acids added to culture solutions.

\begin{tabular}{l|lcr}
\hline \multicolumn{1}{c|}{ Amino acids } & \multicolumn{3}{|c}{ Quantities } \\
\hline L-Arginine & 1, & 5, & $10 \mathrm{mg} \%$ \\
L-Tyrosine & 0.5, & 1, & $5 \mathrm{mg} \%$ \\
DL-Isoleucine & 0.5, & 1, & $5 \mathrm{mg} \%$ \\
L-Glutamine & 1, & 10, & $20 \mathrm{mg} \%$ \\
L-Leucine & 0.5, & 1, & $5 \mathrm{mg} \%$ \\
L-Proline & 0.5, & 1, & $5 \mathrm{mg} \%$ \\
DL-Tryptophane & 0.5, & 1, & $5 \mathrm{mg} \%$ \\
DL-Phenylalanine & 0.5, & 1, & $5 \mathrm{mg} \%$ \\
DL-Serine & 1, & 2, & $5 \mathrm{mg} \%$ \\
DL-Threonine & 1, & 2, & $5 \mathrm{mg} \%$ \\
DL-Alanine & 1, & 5, & $10 \mathrm{mg} \%$ \\
\hline
\end{tabular}

The effect of amino acids was not clear. The thalloid form grew as the thalloid form. On the contrary, the filamentous form sometimes grew into a thalloid form, although at times it remained as the filamentous form.

Experiment 5. Constituents of the enrichment solution were examined to determine any effect on the growth or the form. The culture solution was medium 3 and the inocula employed were both filamentous and thalloid form. The constituents tested and their quantities employed were as follows (Table 6):

With the exception of 2 instances, $B_{12}$ caused the filamentous form to grow into the thalloid form.

Table 6. Constituents added to culture solution.

\begin{tabular}{|c|c|c|c|}
\hline \multirow{2}{*}{$\begin{array}{l}\text { Constituents } \\
\mathrm{NaNO}_{3}\end{array}$} & \multicolumn{3}{|c|}{ Quantities } \\
\hline & 2 & 20 & $200 \mathrm{mg} \%$ \\
\hline $\mathrm{Na}_{2}$ glyceroPO $\mathrm{P}_{4}$ & 0.1 & 1 & $10 \mathrm{mg} \%$ \\
\hline $\mathrm{FeCl} \cdot 6 \mathrm{H}_{2} \mathrm{O}$ & 0.05 & 0.5 & $1 \mathrm{mg} \%$ \\
\hline $\mathrm{MnCl}_{2} \cdot 4 \mathrm{H}_{2} \mathrm{O}$ & 0.01 & 0.1 & $1 \mathrm{mg} \%$ \\
\hline $\mathrm{CoCl}_{2}$ & 0.01 & 0.1 & $1 \mathrm{mg} \%$ \\
\hline NasETA & 0.1 & 1 & $10 \mathrm{mg} \%$ \\
\hline $\mathrm{H}_{3} \mathrm{BO}_{3}$ & 0.1 & 1 & $10 \mathrm{mg} \%$ \\
\hline Tris & 10 & 100 & $500 \mathrm{mg} \%$ \\
\hline Vitamin $B_{12}$ & $10 \mathrm{rm}$ & $100 \gamma \mathrm{m}$ & $1 \gamma \%$ \\
\hline
\end{tabular}

Experiment 6. In experiment 3, 4 and 5, medium 3 was used as the base medium. Medium 3 alone did not help the plant grow normally except for a few cases. Furthermore, thalloid forms at times stopped growing and produced the filamentous forms with protuberances like branches. It is considered that some bacteria helped the plant grow normally when medium 3 alone worked on the plant. As a matter of fact, it has been 
observed many times that the plant grows normally or filamentous forms become thalloid when unsterilized medium 3 was used.

From the above mentioned facts, the following experiment was planned to elucidate what bacteria would influence the morphogenesis of the plant. Bacteria were isolated after streaking the plant on agar surface of the isolation medium (Table 7). Then bacteria were transfered to the bacteria-free culture of the filamentous form of the plant. Among several strains isolated, one was found to have effect on the morphogenesis. This bacterium was tried 7 times to determine if it really worked on the growth or the form. In 5 instances the plant became the normal form with that bacterium. The plants were known not to be bacteria-free later and this might be the reason that in 2 instances the plant still remained the abnormal form. Although the cultures were found impure, the success of culturing, though 5 out of 7 , seemed to show that the isolated bacterium worked on the morphogenesis.

Table 7. Isolation medium.

$\begin{array}{lc}\text { Artificial sea water (Table 1) } & 100 \mathrm{ml} \\ \text { Peptone } & 0.5 \mathrm{~g} \\ \text { Meat extract } & 0.2 \mathrm{~g} \\ \mathrm{KNO}_{3} & 0.05 \mathrm{~g} \\ \mathrm{Agar} & 1.5 \mathrm{~g}\end{array}$

\section{Discussion}

The experiment 1 and 2 suggested that the transformation of Grinnellia americana was derived from the micronutrients contained in the sea water. The experiment 3 and 5 showed that $B_{12}$ worked on the growth or the morphogenesis. The alga would not grow without $B_{12}$ or in small concentrations of $B_{12}$, although it remained alive. In this unfavourable condition, the plant produced protuberances like branches which remained alive quite a long time. They grew into a normal new plant when the environmental condition was recovered to the favourable one, that is, they grew into normal plants in the medium 1 or the medium 3 after addition of $\mathbf{B}_{12}$. This demonstrates a unique way to endure the unfavorable condition. The plants grew normally in experiment 4 and this seemed to be due to the growth of bacteria with the concentration of amino acids, because the plant grew normally with any of the amino acids, and the growth of bacteria was most prominent. The bacterium that converted the plants from the abnormal form to the normal might produce $B_{12}$ in its environment, as $B_{12}$ was found to work on the morphogenesis. It is interesting to note that ERICSON and LewIS $^{2 \gamma}$ have reported marine bacteria producing $B_{12}$. The metabolites of bacteria have to be investigated before describing the relation of the plant and bacteria with any certainty. However it might be 
said that $\mathrm{B}_{12}$ is a key substance in determining the direction of the metabolism, and the morphogenesis of this alga, Grinnellia americana (C. AgardH) HARveY. Thus it appears. that metabolites produced by microorganism have an important significance in the metabolism of algae.

\section{Summary}

1. Grinnellia americana (C. Agardh) HaRvey grew abnormally, appearing as a filamentous form when cultured with the sea water of Urayasu at the bottom of Tokyo Bay, though it grew normally with sea water from the mouth of Tokyo Bay.

2. After examining the effect of the vitamin $B$ group and amino acids on the morphogenesis of Grinnellia americana, vitamin $\mathrm{B}_{12}$ was found to convert the abnormal form of the plant to the normal one in some instances.

3. Several strains of bacteria have been isolated from the surface of Grinnellia americana and one strain converted the abnormal form to the normal form in the 5 instances out of 7 .

4. It was described that the bacterium which affected the morphogenesis might produce vitamin $B_{12}$ in the environment, and $B_{12}$ might be the key substance in determining. the morphogenesis of Grinnellia americana.

\section{References}

1) L. Provasoli: Biol. Bull., 114, No. 3, 375-384 (1958).

2) L. E. Ericson and L. Lewis: Arkivf. Kemi, 6, 427 (1953). 